\title{
Cultivation of Grafted Vegetables II. Development of Grafting Robots in Japan
}

\author{
Kenji Kurata \\ Department of Agricultural Engineering, University of Tokyo, Yayoi 1-1-1, Bunkyo-ku, Tokyo 113, Japan
}

\section{INTRODUCTION}

Grafted seedlings are used commonly in commercial vegetable culture in countries such as Korea and Japan, where land use is intensive. Lee (1994) has reviewed the physiological aspects of grafting. The percentage of cultivated area of grafted seedlings in outdoor commercial vegetable culture amounts to $81 \%$ in Korea and 54\% in Japan (Table 2 in Lee, 1994). In greenhouse cultivation, the percentage is higher in Japan (69\%) and remains the same in Korea (81\%). In particular, almost all watermelon [Citrullus lanatus (Thunb.) Matsum. \& Nakai] seedlings are grafted in both countries.

Grafting is labor intensive. Farmers must manually graft numerous seedlings within a limited period. Neighboring farmers often graft seedlings in cooperation. An analysis of such group grafting showed that production of $\approx 3000$ grafted cucumber seedlings required $6 \mathrm{~h}$ of labor from seven persons (Kobayashi, 1991). About $70 \%$ of the time was devoted to joining.

As the average age of farmers increases, farmers' demand for grafted seedlings increases. Several million grafted seedlings are produced by nurseries or by agricultural cooperatives every year in Japan. However, these organizations are also suffering from a labor shortage. Although the processes of filling trays with soil, seeding, watering, and controlling the growth environment are automated in some nurseries, grafting is done manually. Thus, developing automated grafting robots, which produce uniform seedlings at a lower cost, is a high priority.

Much effort has been devoted to developing grafting robots in Japan, although none of them have yet come into practical use. This report describes four robots under development.

\section{JT'S ROBOT}

Japan Tobacco Inc. (JT) has developed a prototype grafting robot. The robot uses special tubes for joining rootstock and scions and

\footnotetext{
Received for publication 5 Apr. 1993. Accepted for publication 31 Aug. 1993. I thank Japan Tobacco Inc., Techno Grafting Research Inc., and Bio-oriented Technology Research Advancement Institution for providing materials (in particular figures and photographs) for this article and Nancy Okamura for assistance in preparing this article. The cost of publishing this paper was defrayed in part by the payment of page charges. Under postal regulations, this paper therefore must be hereby marked advertisement solely to indicate this fact.
}

securing them. The tubes are plastic and shrink when heated (Fig. 1). Rotary disc cutters cut the stems of rootstock and scion seedlings at an angle to the axes. The scion and the rootstock stems are joined within the tube. Then, the tube is heated by hot air at 150 to $250 \mathrm{C}$ for several seconds. The tube shrinks and secures the graft union. Then, the tube is cooled to ambient temperature by cool air.

The inner diameter of the tube at ordinary temperatures is large enough to enable smooth insertion of scion and rootstock stems. When heated, however, the tube shrinks not only longitudinally, but also radially. Therefore, the graft union is pressed both radially and axially, so that it is secured and supported tightly. Additional advantages of this heat-contracting tube are 1) the tube suppresses transpiration from the graft union and increases the rate of successful grafting, and 2) heat surface-sterilizes the stem. Removing the tubes after grafting is not required, because as the grafted seedlings grow, the tubes drop down by themselves. For cases in which the tubes do

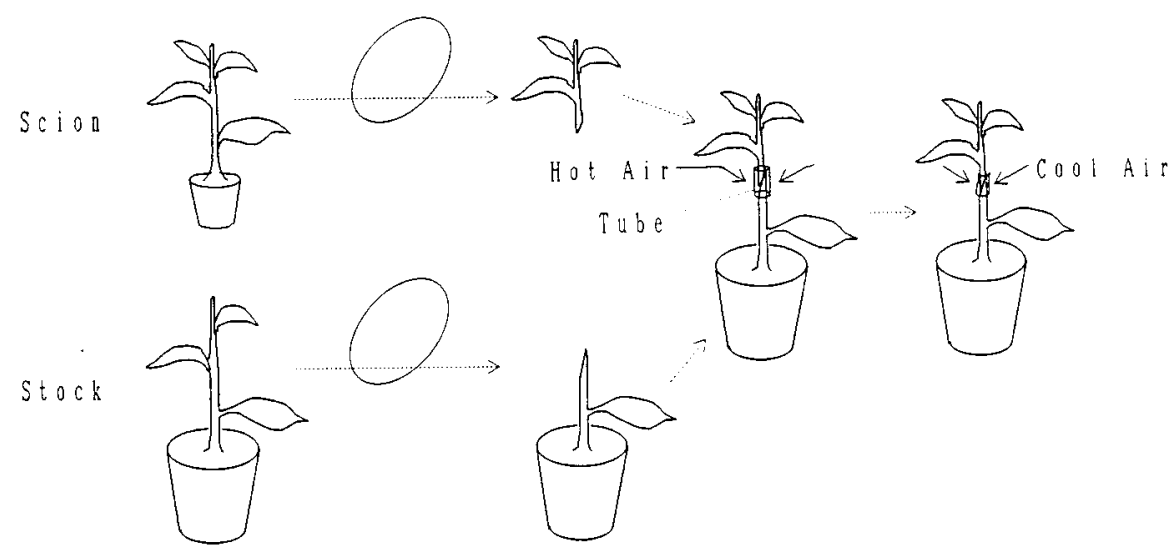

Fig. 1. Schematic of JT's grafting method (courtesy Japan Tobacco, Inc.).

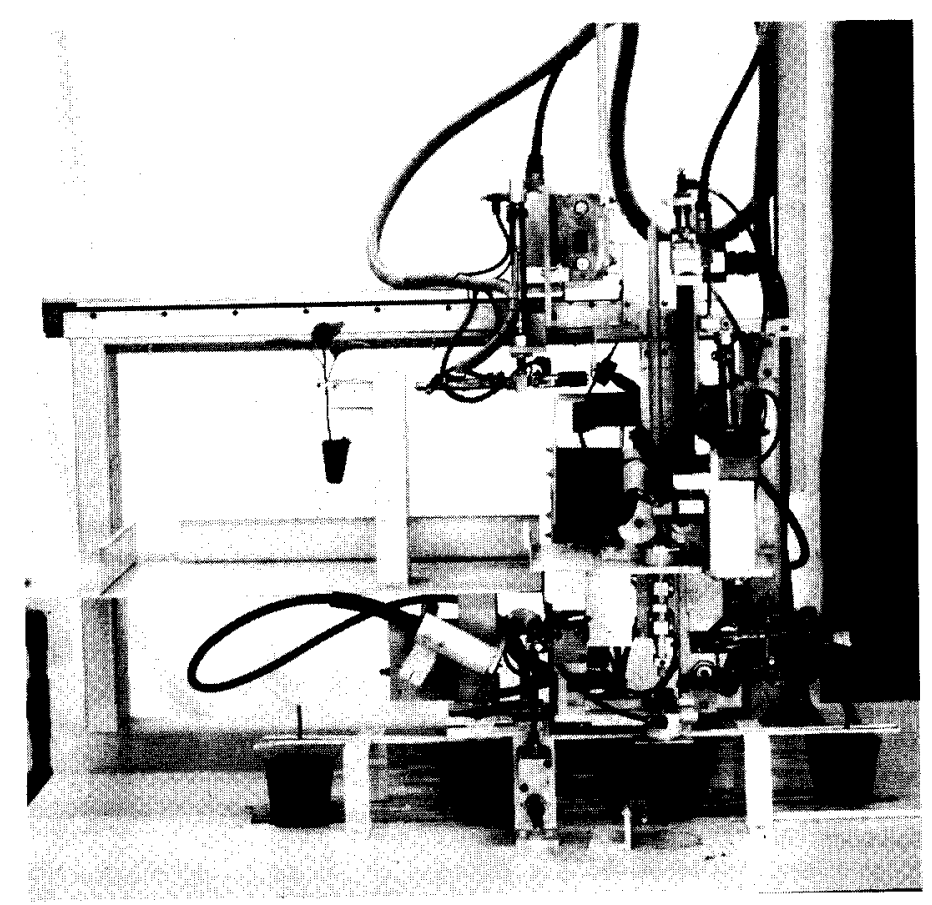

Fig. 2. JT's robot (courtesy Japan Tobacco, Inc.). 


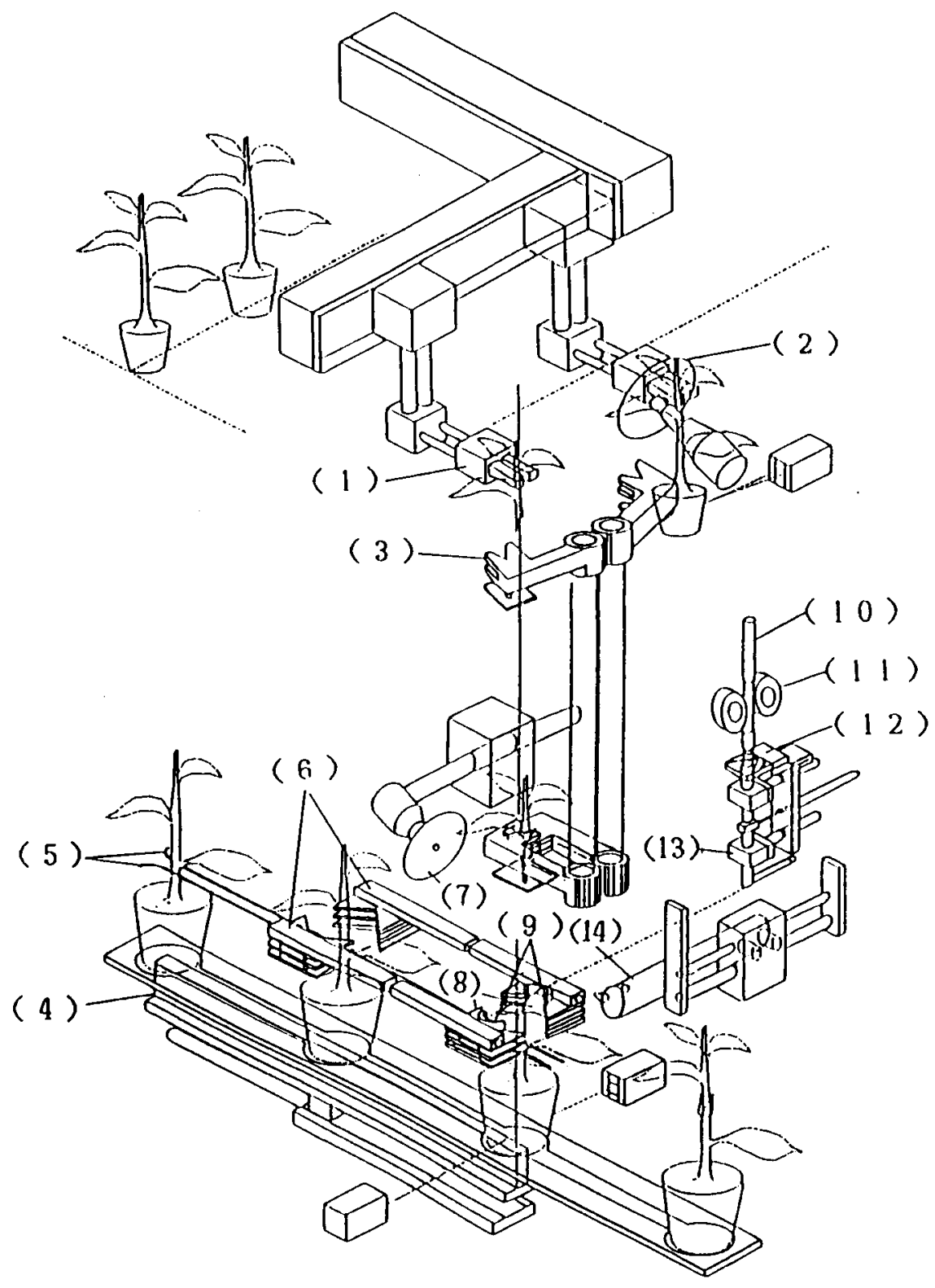

Fig. 3. Main parts of JT's robot: $(1,3)$ scion transport arms; (2) rotary disc cutter for scion; (4) rootstock transport base; (5) pair of guide arms for rootstock transport; (6) pair of guide arms for cutting rootstock; (7) rotary disc cutter for rootstock; $(8,9)$ joining unit; $(10-12)$ tube supply unit; (14) hot air supply unit (courtesy Japan Tobacco, Inc.).

not drop down naturally, perforated tubes or tubes with gaps can be used.

Figure 2 shows a photograph of the robot and Fig. 3 illustrates its main parts. The tube supply unit (10-12 in Fig. 3) cuts off a piece of tube of appropriate length and transports the piece to the joining unit $(8,9)$. The arm (1) transports a scion seedling to the rotary disc cutter (2), which cuts the stem. Another arm (3) carries the scion to the joining unit and inserts the scion vertically from above into the tube. The tube is then fixed to prevent vertical movement. The stem of a rootstock seedling is cut by the rotary disc cutter and the rootstock is transported, guided by a pair of arms (5), and positioned beneath the joining unit. The rootstock is inserted into the tube from below. Then, the tube is heated by air supplied from
Figure 4 schematically illustrates the grafting method adopted by TGR, and Fig. 5 shows the grafting process. Rootstock and scion seedlings are grown in a tray that is divided into square cells. Each cell contains one seedling. All of the scion seedlings in a row are grafted simultaneously onto a row of rootstock seedlings. Two pairs of supporting plates, one on top of another (Fig. 4), are introduced into the space between the scion seedling rows and simultaneously support all of the scion seedlings in a row (Fig. 5A); then, the scion seedlings are cut below the supporting points. Similarly, the rootstock seedlings in a row are supported by two pairs of supporting plates and cut above the supporting points (Fig. 5B). The scions are transported by the supporting plates onto the rootstock, and the positions of the plates are adjusted so that each scion is aligned with a rootstock. Then, the second and third pairs of supporting plates from above (the middle pairs) are removed. Scions and rootstock are joined and secured with an adhesive (Fig. 5C), and grafting is completed when the remaining two pairs of supporting plates are removed (Fig. 5D). No data on the performance tests of this robot have yet been published.

TGR is working to complete a mass production system for grafted seedlings, which includes the robot noted. For this purpose, germinating seeds at the desired positions and rate, growing uniform seedlings, and acclimatizing grafted seedlings have been investigated.

\section{BRAIN'S ROBOTS}

Bio-oriented Technology Research Advancement Institution (BRAIN) has developed first, second, and third prototype grafting robots. In the adopted grafting method, a growing point and one cotyledon are cut off from the rootstock seedling, and the root is removed from the scion seedling. The rootstock and the scion are joined and held in place by a clip. Figure 6A shows the second prototype's system. The two wheels in the foreground are seedling supply units. Each wheel has 20 U-shaped openings on the perimeter from which seedlings are hung. Seedlings are supplied manually to the wheels. Rootstock seedlings are set so that their cotyledons coincide with the radial direction of the wheel (right wheel in Fig. 6A), while the cotyledons of scion seedlings are tangential to the wheel (left wheel). Both wheels rotate and feed seedlings to the gripping and transporting units, the two small discs behind the wheels in Fig. 6A. Both discs have the same structure but turn in opposite directions. Figure 6B shows the disc for gripping and transporting rootstock seedlings. Each disc has three seedling grippers equally spaced along the perimeter. The discs rotate and stop at $120^{\circ}$ intervals. Three functions are performed as the seedlings are rotated around the discs: 1) a gripper receives a seedling from the wheel; 2) the seedling is cut; 3 ) the seedling is joined to another seedling, fixed with a clip (Fig. 6C), and released from the gripper. The right part of Fig. 6B shows the cutting unit for 

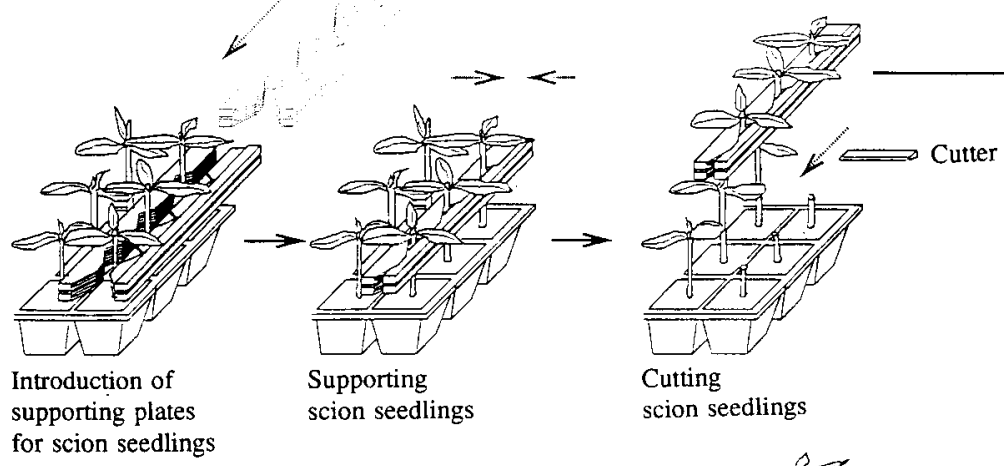

for scion seedlings

scion seedlings
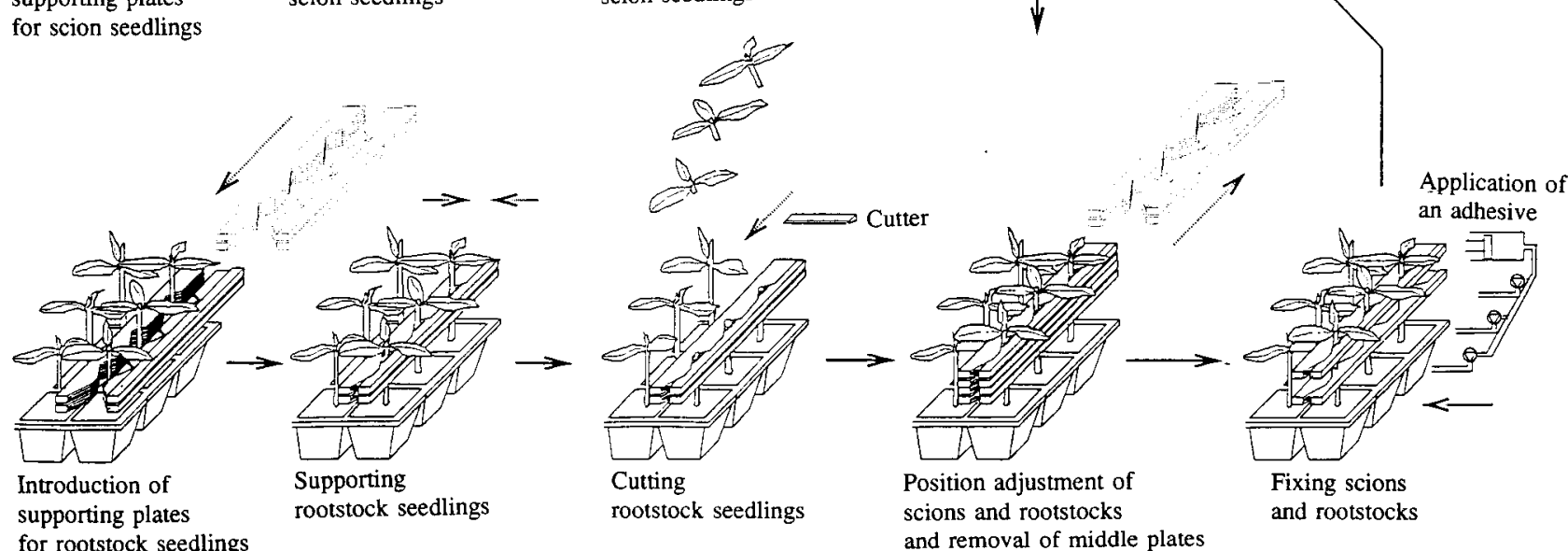

Position adjustment of

scions and rootstocks

Fixing scions

and removal of middle plates

Removal of remaining plates

Application of an adhesive

Fig. 4. Schematic of TGR's grafting method (courtesy Techno Grafting Research, Inc.).
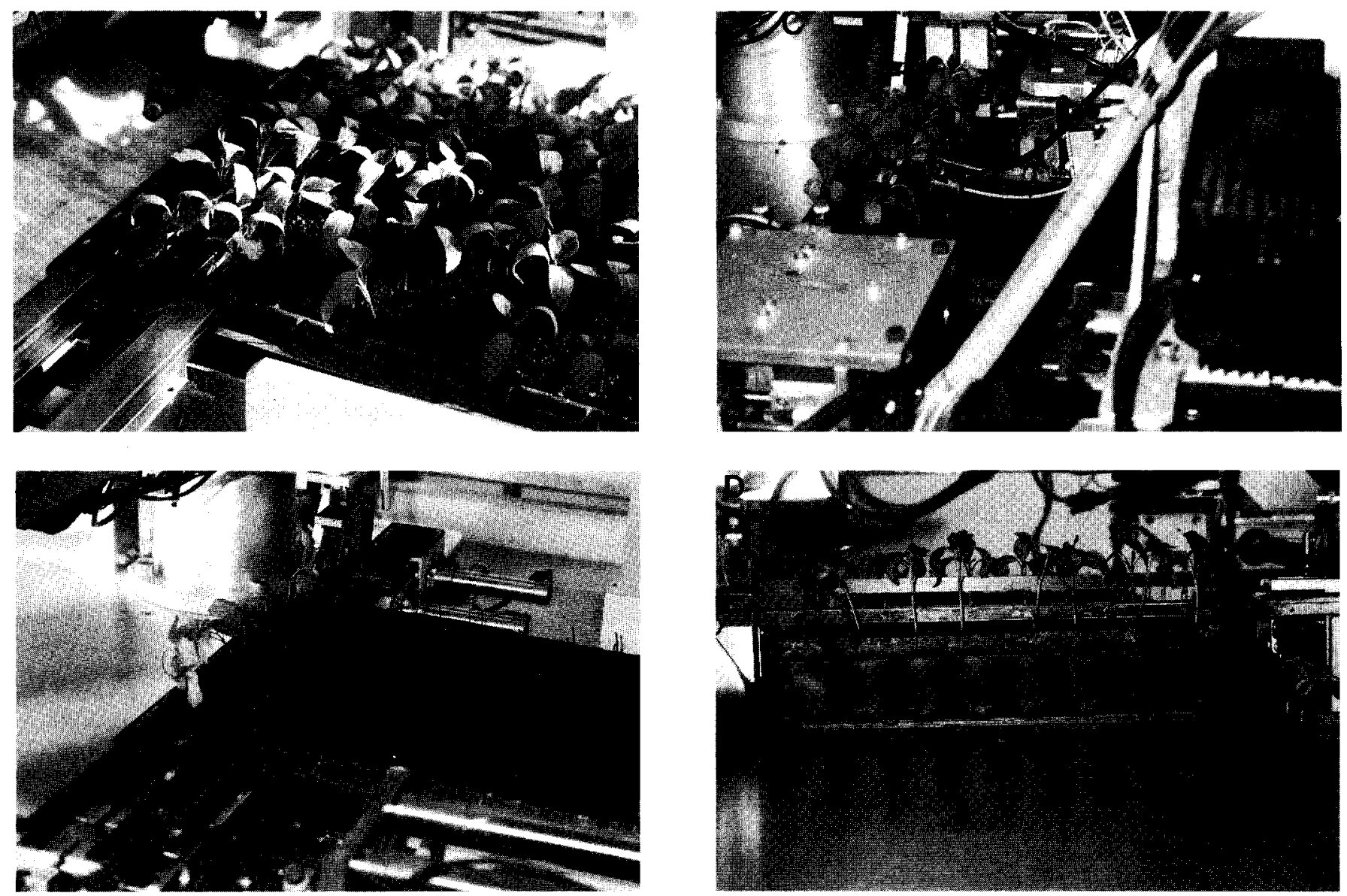

Fig. 5. TGR's robot. (A) Supporting all scion seedlings in a row with plates;(B) cutting rootstock seedlings in a row; (C) fixing the joints with an adhesive;(D) grafted seedlings (courtesy Techno Grafting Research, Inc.). 

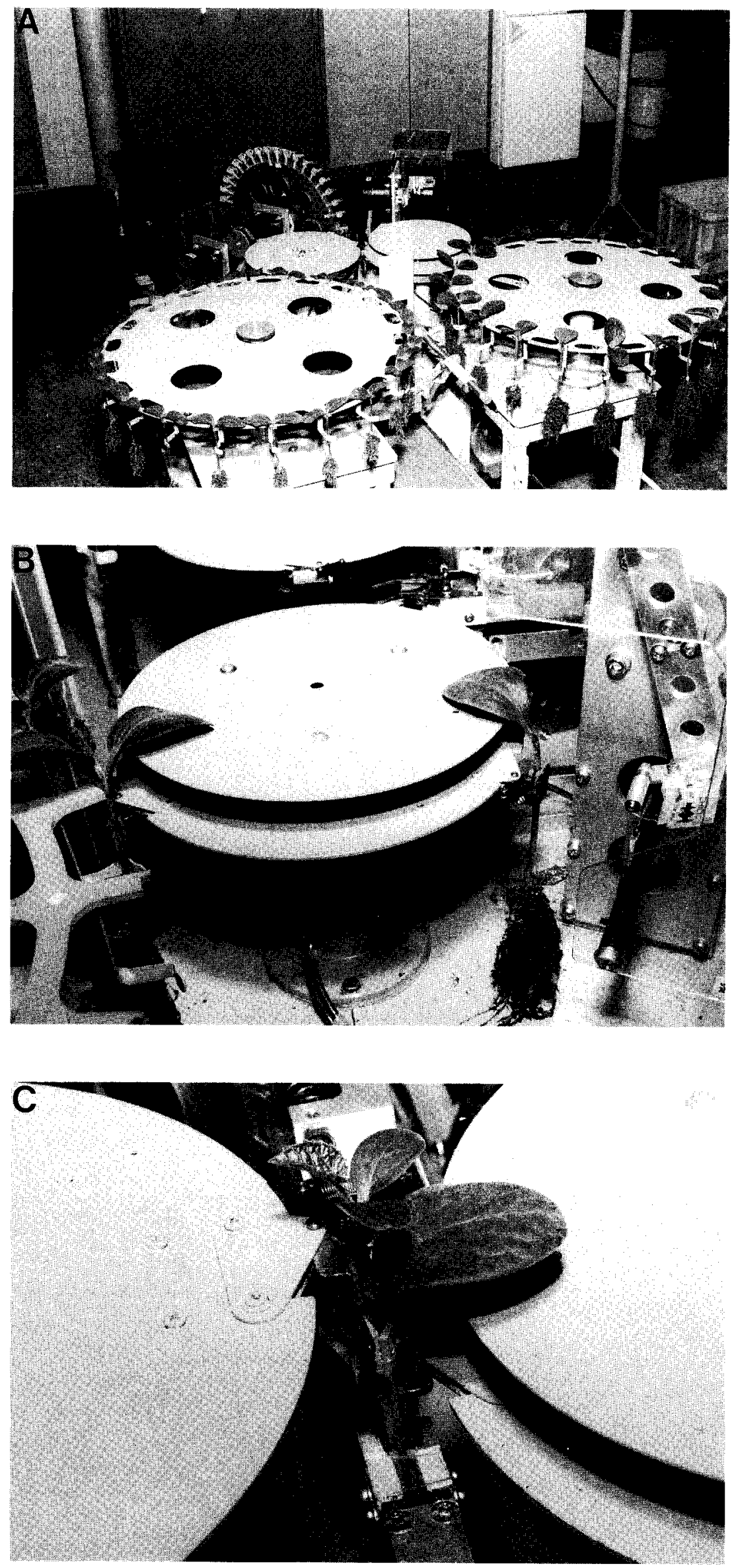

Fig. 6. BRAIN's second prototype grafting robot. (A) Whole system; (B) gripping and transporting unit; (C) fixing unit (courtesy of Bio-oriented Technology Research Advancement Institution). rootstock seedlings. The unit has an arm with a razor blade at the tip. The arm turns and cuts off one cotyledon and a growing point from the rootstock seedling. The scion seedling cutting unit has the same structure. In the space between the two discs, the rootstock and the scion are joined and fixed with a clip. Performance tests of grafting cucumber resulted in $98 \%$ of 60 seedlings joined successfully and fixed mechanically. After acclimatization, $95 \%$ of the seedlings were grafted successfully. The time required to produce one grafted seedling was $\approx 3 \mathrm{sec}$.

Figure 7 shows the third prototype, which has been developed based on experiments using the second prototype. Unlike the second prototype, trays containing seedlings are supplied to the system instead of supplying individual seedlings manually. The tray is divided into 48 cells, and each cell can be separated from the tray. Each seedling in a cell is transported onto a turn table, and the cotyledon orientation is photoelectrically detected and adjusted. Results of performance tests have not yet been published.

\section{HONAMI ET AL.'S ROBOT}

Honami and coworkers have developed a robotic grafting system based on a new grafting method, which they named "plug-in method" (Honami et al., 1992). Perfectly joining the vascular bundles of scion and rootstock can be expected to promote smooth water and nutrient transport between scion and rootstock and, as a result, lead to higher physiological activity of the grafted seedling. The plug-in method has been proposed as an improved technique to minimize malconnection of vascular bundles. In this method, the scion tip is shaped into a conical form. For tomato (Lycopersicon esculentum Mill.) or eggplant (Solanum melongena L.) scions, stems are processed into a plug shape having a tapered tip ( $14^{\circ}$ and $10 \mathrm{~mm}$ of processed length) using a vibration cutter (115 Hz frequency). A taper drill (4500 rpm) makes a conical hole in the rootstock. The conically shaped scion is then plugged into the conical hole of the rootstock and the graft is complete. Because of the high bond strength, there is no need for supplementary devices to support the joined portion. A prototype robotic system for this grafting method was developed and tests using tomato, eggplant, and watermelon resulted in rapid joining and excellent growth of grafted seedlings.

\section{CONCLUSION}

Thus far, no robot is used for commercial grafting in Japan. However, as shown above, private companies, institutions, and universities are attempting to develop feasible grafting robots, and, in the near future, it will be common practice for growers to buy seedlings grafted by robots. 


\section{Feature}

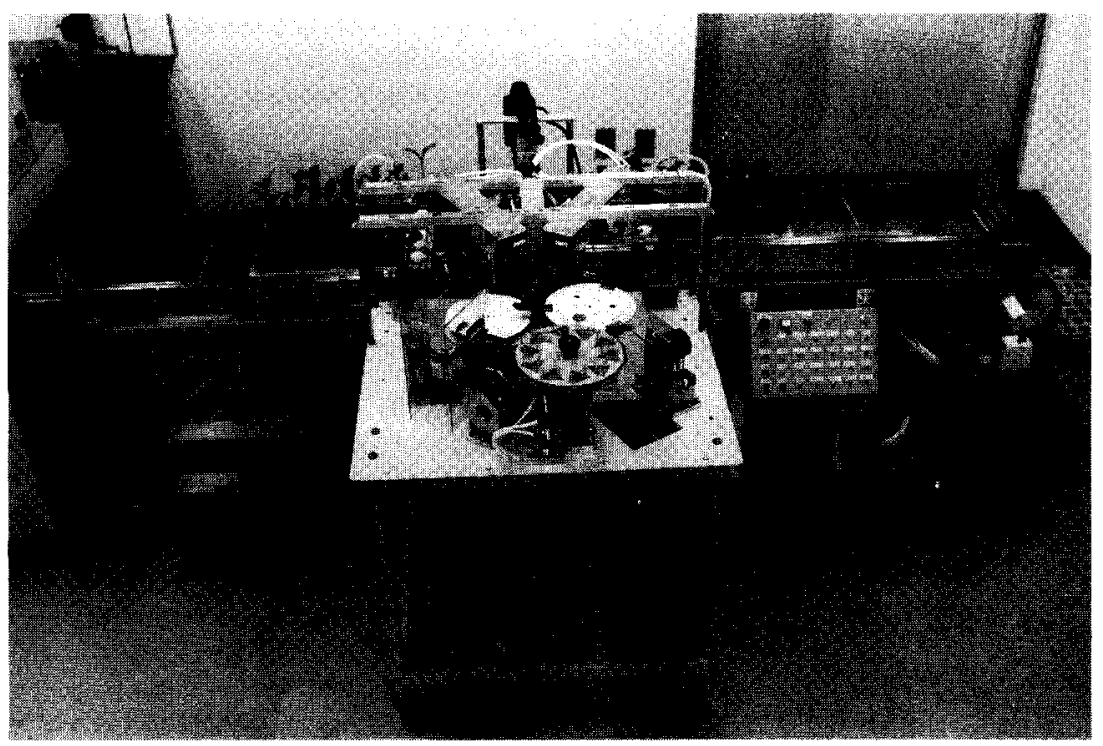

Fig. 7. BRAIN's third prototype grafting robot (courtesy of Bio-oriented Technology Research Advancement Institution).

\section{Literature Cited}

Honami, N., T. Taira, H. Murase, Y. Nishiura, and Y. Yasukuri. 1992. Robotization in the production of grafted seedlings. Acta Hort. 319:579584.

Kobayashi, K. 1991. Development of a grafting robot for fruits-vegetables (in Japanese). Plant Cell Technol. 3(6):477-482.

Lee, J.-M, 1994. Cultivation of grafted vegetables. I. Current status, grafting methods, and benefits. HortScience 29:235-239.

Manzawa, K., H. Saito, Y. Irie, and T. Mitani. 1992. Development of an automated grafting machine for eggplant seedlings. Abstr. Intl. Symp. Transplant Production Systems, Yokohama, Japan. p. 101. 